\title{
A questão da língua na escola indígena em aldeias Paresi de Tangará da Serra-MT
}

\author{
Maria Helena Rodrigues Paes \\ Universidade do Estado de Mato Grosso, Campus de Tangará da Serra
}

\section{Introdução}

Apresento neste artigo os caminhos percorridos e algumas reflexões, na perspectiva dos Estudos Culturais, que permearam uma investigação diante da situação de conflito quanto ao papel da escolha e valorização das duas línguas envolvidas - língua portuguesa e língua materna no contexto de escolarização nas aldeias indígenas Paresi de Tangará da Serra-MT. $\mathrm{Na}$ referida investigação foram priorizadas as vozes indígenas como fonte de dados, com base nas quais se desenhou uma análise textual.

É importante mencionar aqui a diversidade das populações indígenas brasileiras que se apresentam em diferentes contextos nas relações com a sociedade envolvente. Umas já totalmente capturadas pelos códigos simbólicos ocidentalizados, inclusive pela língua portuguesa (para muitos não mais considerados indígenas), algumas, que mantêm fortes suas expressões tradicionais de vida e costumes (muitas vezes erroneamente denominadas "índios puros") e outras ainda que vivem na fronteira entre essas duas expressões. Neste trabalho abordo situações de um povo específico: o Paresi, que mantém forte seu apego cultu- ral tradicional, tendo na língua materna a expressão de sua identidade étnica (afirmação dos próprios $\mathrm{Pa}$ resi), porém em intenso contato com a sociedade ocidentalizada, capturando de tal sociedade inúmeros artefatos culturais, os quais são aos poucos incorporados em sua rotina diária. Desta maneira, faz-se imprescindível a reflexão do discurso da valorização da língua portuguesa, na rotina da escola da aldeia, considerando-se a função e o papel da escola para essa comunidade.

\section{0 global e o local: a grande mistura}

Não há mais como não perceber e tomar consciência das mudanças, em escala mundial, provocadas pelo crescente processo de globalização. Tal processo tem como alavanca principal as tecnologias de informações que tornam os povos mais próximos entre si, embora nem sempre, os homogeneizando. As informações, atualmente, circulam com rapidez, tanto no interior das grandes metrópoles quanto nas populações de lugares mais distanciados, que acompanham, mesmo que somente por imagens de televisão, os acontecimentos nas mais diversas partes do mundo. 
A mídia, tendo na televisão e no rádio seus mais fortes representantes, informa em velocidade espantosa as mais novas expressões, valorizadas ocidentalmente, de como se vestir, comer, o que ouvir e a importância de dominar uma língua nacional reconhecida, ou ainda, uma língua de valorização universal. Nessa mesma perspectiva, os habitantes, já não mais de locais isolados, vão sendo capturados pelas mais inovadoras expressões do "ser" e "viver". Aos poucos, vão transformando suas rotinas e habitando diferentes mundos, hibridizando-se num movimento de fluxo contínuo na construção de identidades cambiantes, fluidas, não no sentido pejorativo, mas numa perspectiva de construção e reconstrução de modos de sobreviver em uma realidade cada vez mais permeada por novas tecnologias no uso dos instrumentos diários.

Hall (2000), ao comentar os efeitos da pluralização de culturas nacionais e de identidades nacionais, lança o questionamento do qual me apodero neste texto: "É possível, de algum modo, em tempos globais, ter-se um sentimento de identidade coerente e integral?" (p. 84).

Por mais isoladas geograficamente que estejam essas populações consideradas minorias, inserem-se também no movimento da informação e da instrumentalização tecnológica que o mundo ocidentalizado capitalista produz e oferece como alternativas de melhoria de qualidade de vida, transformando esses instrumentos em artefatos necessários e imprescindíveis ao que se chama, hoje, de mundo moderno. ${ }^{1} \mathrm{~A}$ pretensa "necessidade" de utilização desses instrumentos vai formando novas identidades e novas expectativas de modos de vida. Tais populações configuram uma forma híbrida de ser e viver, para não serem expurgadas do mundo globalizado. As minorias étnicas, para sentirem-se pertencentes a esse mundo globalizado, subjetivam-se nesta nova forma de ser construindo novos valores no interior de seus gru-

${ }^{1}$ Tomo aqui o uso deste termo no sentido de alternativas de sobrevivência que não a tradicional, baseada em instrumentos artesanais. pos. Canclini (1999), ao tratar das identidades em tempos de globalização, afirma: "hoje a identidade, mesmo em amplos setores populares, é poliglota, multiétnica, migrante, feita com elementos mesclados de várias culturas" (p. 166).

Não desejo com isso deixar transparecer a idéia de que a hibridez é marca característica somente de povos de minorias étnicas; ao contrário, considero que não há mais como se pensar em indivíduos e identidades puras e cristalizadas, mesmo em países de culturas ocidentalizadas e que se pensam hegemônicos e homogêneos. Na medida em que as fronteiras do mundo se alargam e se enfraquecem, as trocas culturais são cada vez mais freqüentes e possíveis, deixando as culturas e as identidades cada vez mais em condições de serem capturadas e atravessadas por expressões culturais das mais diversas naturezas e origens. Com esta afirmação, estou rejeitando uma posição etnocêntrica, que pode circular entre muitos que pensam a hibridez e a "mistura" como característica recorrente do "outro", do mais fraco, do colonizado que não foi capaz de resistir aos processos de inter-relações e manter seus padrões culturais tradicionais, reconhecendo e aceitando, assim, sua cultura como "subalterna" e "inferior".

Evidentemente são inúmeros os elementos articuladores de novas configurações culturais, porém recorto especificamente, neste artigo, o processo de escolarização como ferramenta e espaço negociador de significados de mundo, promovendo, neste sentido, invenções e reinvenções que, sem dúvida, contribuem para as novas configurações de identidades e significados no interior de determinada comunidade. Assim, a escola, além de trazer novos conceitos e valores de mundo (sob a perspectiva da sociedade ocidentalizada), construídos e estabelecidos como "verdades absolutas", carrega também uma possibilidade de construção e configuração de novos sujeitos e novas identidades, que, nas relações entre si, produzem novas performances de grupo. A construção curricular e todos os elementos nela envolvidos (atividades, objetos, posturas corporais, práticas, divisões de tempo e de espaço, práticas de avaliação etc.) funcionam a fim de produzir subjetividades e construir 
formas de vida em sociedade. A escola, então, atua por meio de saberes e poderes, na subjetivação de um indivíduo e de um povo, redirecionando suas alternativas e seus instrumentos de sobrevivência.

\section{Especificamente falando sobre os índios}

A questão indígena tem se revelado um tema de grande interesse nos mais diversos setores do cenário nacional e, desta forma, a educação indígena configura-se como uma área de especial atenção no Estado de Mato Grosso, onde o poder público tem implementado políticas públicas que visam garantir o que a Constituição Federal de 1988 assegura quanto à especificidade nos processos formais de educação de cada etnia. Nesse sentido, busca-se a construção de escolas específicas e diferenciadas, rompendo com as metanarrativas disciplinares unificadoras que atendem aos padrões do conhecimento universal e partindo para ações que consideram os saberes relacionados diretamente com o grupo e a realidade local, valorizando-os, numa negação ao processo de homogeneização incrustado no modelo da escola de postura tradicional.

\section{O Paresi}

O grupo Paresi, que se autodenomina Haliti - o povo verdadeiro -, é habitante natural da região noroeste do estado de Mato Grosso e caracteriza-se, apesar do intenso contato com a sociedade envolvente, por ainda manter fortes seus costumes e traços culturais tradicionais, como a roça de toco, a caça, as festas tradicionais, os jogos, as pajelanças etc. Com grande apego mítico, os cerca de 1.400 Paresi são falantes fluentes de sua língua materna, do tronco Aruak e dividem-se em mais de 30 aldeias, de baixa densidade demográfica, caracterizadas pelas construções das casas tradicionais denominadas Hati. Embora de tradição oral, com o processo de escolarização e o intenso movimento de inter-relação de diversas naturezas com os não-índios vizinhos, a escrita e o domínio da língua portuguesa têm se revelado elemento imprescindível para sobrevivência desse povo, como será apontado em seção posterior neste artigo.

Os primeiros contatos com os Imuti $^{2}$ aconteceram sob o signo da violência e do uso de sua mão-de-obra, quando exploradores de látex e poaia ${ }^{3}$ chegaram à região ainda no início do século XX. A partir dessa época, esses contatos se intensificaram facilitados pela abertura de uma estrada federal que cortava a grande área paresi. Por volta do início dos anos de 1970, muitos latifundiários passaram a utilizar as terras vizinhas para o cultivo de grandes lavouras mecanizadas, nas quais os índios passaram a se empregar como mão-deobra não qualificada para o cultivo da terra.

Atualmente os Paresi vivem num mundo estruturado sob forma fronteiriça, no qual os instrumentos tradicionais se misturam aos elementos característicos da cultura ocidental. Assim, é comum entrarmos em uma Hati na qual se entrelaçam elementos das duas culturas: fogão a gás, xiris, guarda-louças, bacarás, mesa de fórmica, arco, flecha, aparelhos de som, cabaças de chicha, massa de mandioca para beiju, redes com cobertores, lençóis e travesseiros. A alimentação também tem se caracterizado pela constituição híbrida, sendo comum o uso de margarina ao comer um beiju ou uma boa carne de caça moqueada acompanhada por arroz feito à base de óleo industrializado e uma dose de refrigerante ou suco artificial.

A questão da circulação das informações, que antigamente acontecia somente pela oralidade, atualmente lança mão do rádio amador, do rádio de transmissão por ondas médias e ainda do telefone celular, que tem sido o mais novo aparato tecnológico a adentrar as rotinas informativas do grupo.

A história da escolarização entre os Paresi data da época de Marechal Rondon, por volta de 1920, quando em missão de instalação das linhas telegráficas. Com sua política de integração e "civilização" do indígena brasileiro, estabeleceu fortes e amistosas relações com o grupo, tornando-se figura de referência para os Pare-

\footnotetext{
${ }^{2} \mathrm{O}$ termo Imuti é utilizado pelos Paresi para os não-índios.
}

${ }^{3}$ Poaia é a raiz de uma planta medicinal, muito comum na região e que na época era de grande valor para exportação. 
si. Ele fundou a primeira instituição escolar naquela região, o Internato Utiariti, organizada conforme princípios positivistas e que tinha como objetivo, entre outros, treinar os indígenas para o convívio com a "sociedade civilizada”. Naquela época, esses indígenas, além de receber o ensino das primeiras letras, tinham também noções de higiene, disciplina e cumprimento de horários, de um ponto de vista ocidental, além da aprendizagem da língua portuguesa e, ainda, treinamento de habilidades específicas para o trabalho de manutenção das linhas telegráficas da região. Por volta de 1930, os jesuítas assumiram a escolarização na região, posteriormente executada por outras confissões religiosas, que, além da alfabetização em língua portuguesa, também tinham a missão de "salvar as almas indígenas" por meio da evangelização e da conversão a Cristo.

No final dos anos de 1980 a Prefeitura Municipal de Tangará da Serra assumiu a coordenação e acompanhamento das escolas indígenas, nas quais se implementavam as mesmas orientações e práticas pedagógicas das demais escolas de ensino fundamental do sistema municipal de educação. Por sua vez, a Constituição Federal de 1988, por seu artigo 210, preceitua que "o ensino fundamental regular será ministrado em língua portuguesa, assegurada às comunidades indígenas também a utilização de suas línguas maternas e processos próprios de aprendizagem", garantindo assim a essas comunidades o direito a processos de escolarização diferenciados.

Dessa forma, os governos estadual e municipal, junto às lideranças indígenas, passaram a promover discussões para implementar políticas públicas que atendessem ao preceito da referida Constituição. Ao mesmo tempo, e de acordo com à legislação em vigor, as comunidades indígenas passaram a reivindicar programas de formação para o magistério, já que os professores nativos não tinham a referida habilitação nas aldeias. Em 1996, teve início o Projeto Tucum Programa de Formação de Professores Índios para o Magistério, encerrado no ano 2000 - que se fundamentava na valorização da cultura, terra e da língua. Nesta mesma perspectiva de orientações políticas e metodológicas, técnicos governamentais estaduais e municipais, junto aos professores das escolas indígenas de Tangará da Serra, passaram a desenvolver tentativas de construção de uma escola diferenciada, ${ }^{4}$ com currículo específico, tendo em vista a valorização da cultura e da língua paresi.

Assim como em qualquer processo de transição, muitos problemas e conflitos emergiram e ainda se fazem presentes na rotina escolar das aldeias. Neste sentido, o que mais preocupava e despertava atenção com relação à comunidade indígena era seu descontentamento quanto às mudanças que estavam se processando, considerando a escola da aldeia "fraca"; por conseqüência, alguns pais tiravam suas crianças da aldeia e enviavam-nas para estudar nas escolas da cidade. Em depoimentos informais e também registrados nos arquivos do Projeto Tucum, os próprios professores manifestavam suas incertezas e dificuldades diante da implantação da escola diferenciada. Nestes depoimentos se tornava visível o entendimento da função da escola nas aldeias como instrumento de inserção e pertencimento à cultura ocidentalizada. Entre as reivindicações de escola diferenciada e as vozes inscritas nos relatórios, valorizando o modelo de escola nacional, ${ }^{5}$ percebi o conflito que se apresentava. Foi quando me propus a investigar quais problemas estavam circulando nas escolas das aldeias, motivando a comunidade a negar essa escola que buscava aproximar-se mais da realidade e valorização da cultura local.

\section{A rotina escolar}

As escolas da aldeia atendem crianças do ensino fundamental de $1^{\mathrm{a}}$ a $4^{\mathrm{a}}$ série, basicamente seguindo a estrutura curricular do sistema municipal de ensino. Porém, desde 1999, em discussão com os professores,

${ }^{4} \mathrm{O}$ grupo de professores passou a usar este termo referindo-se a novas metodologias e orientações pedagógicas visando à valorização e inserção de elementos da cultura paresi no conteúdo curricular.

${ }^{5}$ Denomina-se escola nacional às escolas que pertencem ao sistema nacional de educação com currículo padronizado. 
decidiu-se que os alunos já não receberiam mais livros distribuídos pelo Programa Nacional do Livro Didático. Somente os professores teriam acesso a tais livros, com a tarefa de adaptar os conteúdos e metodologias às rotinas presentes em cada comunidade.

Ao iniciar-se no processo de escolarização, a criança paresi geralmente só é falante da língua materna e tem seu primeiro contato mais intenso com a língua portuguesa dentro da sala de aula. Dessa forma, o professor tem que se valer das duas línguas para explicar os conteúdos previamente selecionados, visto que toda a estrutura do sistema escolar se baseia na língua portuguesa. O professor vai "traduzindo" para a língua materna das crianças os conteúdos dos livros didáticos, o que não se revela fácil para a compreensão desses alunos. Mas isso também não é fácil para os professores da aldeia - falantes fluentes da língua paresi pois mesmo que já tenham sua habilitação para o magistério, não têm um domínio proficiente da língua portuguesa e, assim, ainda encontram dificuldade para a compreensão de alguns textos dos livros didáticos.

\section{A busca}

Para a investigação dos problemas que circulavam no processo de transição de escola de princípios tradicionais para uma escola diferenciada, parti de depoimentos dos próprios professores indígenas das escolas das aldeias, adquiridos em entrevistas e registrados nos arquivos do Projeto Tucum. Foram também realizadas entrevistas com a comunidade indígena: pais e antigos alunos - que já haviam estudado nas escolas da aldeia e em escolas da cidade. A escolha de entrevista não-dirigida deu-se pela característica de dinamicidade desta técnica, em um movimento entre interlocutores, no qual os mesmos se interpelam mutuamente construindo sentidos, sem objetivos classificatórios muito menos normativos. Assim considerada, permite reconstruções com base na contextualização espaçotemporal, sendo que a própria leitura está sujeita a certas competências históricas que determinam como deve ser lida, sempre existindo a liberdade de alterar os códigos e ler de outro modo (Arfuch, 1995, p. 32, trad. minha). Desta forma, as vozes poderão ser retomadas e ressignificadas em diferentes contextos.

Para abordar a questão da função e do papel da escola para as comunidades das aldeias indígenas paresi de Tangará da Serra, faz-se necessário compreender que a educação tradicional deste povo é realizada diariamente em todas as atividades da rotina da comunidade; brincadeiras ou qualquer outra atividade têm caráter pedagógico na vida paresi. É no dia-a-dia que se constrói um Haliti e, como afirma Bandeira (1997), para os povos indígenas, com a tradição da oralidade, a escrita é alheia aos processos culturais de ensinoaprendizagem, de educação (p. 40). Assim, não são necessários compêndios e manuais que normatizem a conduta das pessoas, e os mestres são os próprios pais e as demais pessoas adultas da comunidade, num educar contínuo por meio das atividades rotineiras.

A educação escolar apareceu no interior das comunidades paresi em função do contato com o Imuti e, assim, expressa-se como um elemento externo à cultura tradicional. Neste sentido, a título de informação para a compreensão de como se "coloca" a escola na configuração da aldeia, em geral o prédio escolar é construído bem próximo à aldeia, mas não se insere no círculo que forma as casas tradicionais, o que reforça a idéia de exterioridade da mesma.

De tradição na oralidade, ainda amplamente utilizada, principalmente em ocasiões dos convites de festas tradicionais, os Paresi, em virtude do contato com o Imuti, tiveram que desenvolver novas e diferentes tecnologias para os contatos junto com os nãoíndios que traziam inúmeras novidades, entre elas a representação gráfica do que se falava. Foram aos poucos conhecendo a "magia" das letras impressas no papel e descobrindo sua necessidade diante da nova realidade, junto aos homens de outros e diferentes costumes. Lembra-nos Bandeira (1997) que "assim aprendem a escrita como uma entre outras tecnologias da cultura envolvente, mas com interesse especial de aplicações no adentramento da organização jurídicoburocrática da sociedade envolvente" (p. 40).

Bonin (1998) afirma que "o conhecimento 'de fora' assume, no contexto do contato, um caráter novo: 
é algo que precisa ser procurado, cercado e dominado" (p. 140). Desta forma, a condição de compreensão dos códigos ocidentais foi efetivando-se como componente necessário à sobrevivência dos Paresi, que foram sendo capturados pelo discurso da "escola necessária", no qual a escola se instituía como instrumento de possibilidades de adentrar esse mundo novo e que só por meio dela se faria.

Não vamos levar a vida assim como agora, cada vez nós estamos... assim... ficando mais próximos do branco... $\mathrm{E}$ o branco mais próximo de nós, apertando mais ainda, então a gente pode levar os alunos, a criançada a aprender mais, conhecer mais a escrita... como podem se defender... como levar as pessoas mais velhas que não sabem ler, ajudando elas na cidade, como redigir os documentos... (Pai de aluno)

A expectativa que o grupo paresi de Tangará da Serra-MT construiu em relação ao processo de escolarização está intimamente ligada ao sentimento de pertença e trânsito na dinâmica do mundo ocidentalizado, assim como da própria sobrevivência da etnia, tendo em vista as novas configurações das comunidades, como explicitam as seguintes falas:

O branco entrou no nosso meio, muitos brancos, né? Aí precisamos de estudo para acompanhar o ritmo do branco. (Pai de aluno)

Se as crianças não se prepararem... Uns vão enfrentar, trabalhar na fazenda e... vai ficar... levando como nos tempos de muitos anos atrás. Eles trabalhando em troca de, talvez de um objeto que não tem valor, talvez eles vão receber um salarinho muito baixinho que não dá pra cobrir a despesa e a necessidade familiar né? (Professor)

Nesta perspectiva, conhecer e dominar elementos da dinâmica do mundo ocidental, para o Paresi, apresenta-se como importante ferramenta para manutenção e sobrevivência de sua comunidade e, como afirma Bonin (1998) a escola "deve configurar-se como uma possibilidade neste processo de apropriação do conhecimento 'de fora'. Apropriar-se de novos saberes não significa sobrepô-los ao saber tradicional, mas transformá-los em 'caixas de ferramenta"” (p. 141). A escola, então, como instrumento de acesso aos saberes ocidentalizados, apresenta-se como elemento essencial no interior dessas comunidades, com objetivo de transmitir os códigos simbólicos da sociedade envolvente, com a qual as relações se tornam cada vez mais estreitas. O Paresi não quer estar alheio à realidade nacional; quer e precisa participar da dinâmica da sociedade brasileira. Assim, a escola "adquiriu um importante valor instrumental: ir à escola facilita a aprendizagem de novas habilidades e conhecimentos sobre o mundo exterior, necessários para a sobrevivência" (Arellanos \& FreedsonGonzáles, 1998, p. 92, trad. minha).

Tendo em vista sua consciência de minoria étnica, estando cada vez mais cercados pelos não-índios e suas ações pautadas no letramento e formações acadêmicas, para os Paresi a escola configura-se como o instrumento que lhes possibilitará acesso a informações acerca do mundo dos Imuti e de seus instrumentos tecnológicos. Isto fica evidente nas seguintes falas:

A gente tem que preparar, trabalhar os alunos já trabalhando, mostrando a visão do mundo todo, do Brasil do país, que... Nós índios somos a minoria, nós somos poucos, nós somos pouco e nós temos que estar, o professor tem que estar ciente de mostrar pro aluno a realidade. (Pai de aluno)

A tecnologia que eu falo tem o carro, a televisão, os aparelhos de som, o rádio amador, a bicicleta, a máquina fotográfica, a tecnologia do branco que é o futebol... Telefone, tudo isso... Na comunidade, às vezes eu falo pra eles [...]: "Se vocês não estudarem, no futuro, nós não vamos ser nada, a tecnologia do branco vai dominar". Eu falo: “tem o computador, ele faz tudo". Você tá lá longe, você pode... na internet, você pode... conversar com a pessoa pela internet. (Professor)

Embora as recentes discussões sobre a questão da educação escolar indígena caminhem para a valorização da língua materna no interior das rotinas escolares, o domínio da língua portuguesa aparece nos discursos do Paresi como necessário nesse movimento de pertença à sociedade envolvente. Não reconhecendo a escola como espaço de circulação e valorização da língua materna, argumentam que: 
[...] na casa dos alunos, eles falam mais na língua materna... então na escola tem que usar mais na língua portuguesa". (Pai de aluno)

[...] como todos os pais, eles falam que a língua, eles... eles aprendem na casa, na aldeia junto com os mais velhos, com os pais, com os colegas, aí eles falam pra trabalhar mais a língua portuguesa. (Professor)

Porque hoje em dia, tem muita coisa que está aparecendo em todas as aldeias... Os fazendeiros, as autoridades, quando chegam conversam, quase que os alunos não entendem, quase que os alunos não respondem, quem responde são os velhos, por isso que eles querem que os alunos aprendam falar o português, falar muito, entender. (Professor)

Considerando as intensas movimentações e modificações em suas rotinas diárias, sob o influxo das relações com os não-índios, a escola configura-se como o instrumento e espaço articulador que deve encarregar-se de preparar a criança paresi para circular no mundo ocidentalizado. Nesta dinâmica acreditam que, dominando os códigos da língua portuguesa escrita e falada, terão acesso aos bens materiais e sociais que todo cidadão brasileiro tem por direito, situando a língua portuguesa como ferramenta para negociações, de diversas naturezas, com o mundo exterior à sua cultura tradicional, assim como garantia de trânsito neste mundo, do qual também fazem parte.

Então amanhã ou depois o povo vem aí, pergunta, nós não sabemos falar, então isso é de super importância, principalmente hoje a gente tá questionando né? (Pai de aluno)

Participar e estar incluído em uma dada realidade significa utilizar-se de toda instrumentação necessária para negociar esta inserção. No contexto mundial atual, no qual o letramento constitui importante elemento de valorização, reconhecimento social e acesso a uma multiplicidade de bens simbólicos, expressando uma garantia de estabilidade econômica, intelectual e profissional, ser ágrafo pode representar a exclusão desse processo. É por intermédio da palavra escrita, grafada, que se dão as mais importantes negociações e garantias legais para os cidadãos. O mundo ocidental é basicamente construído na e por meio da escrita.
A escola foi constituindo-se historicamente como instrumento essencial, organizado e estruturado para desempenhar tal função. É a escola que traz didaticamente organizado o processo de ensino da leitura e da escrita, como instituição legitimada a transmitir os códigos escritos da língua nacional, sob o qual se estruturam todos os códigos normativos morais, religiosos, jurídicos, econômicos etc. Não que a apreensão destes códigos não possa se realizar, em certa medida, informalmente, mas há uma construção social da valorização da formação escolar. Assim, os Paresi são capturados pela concepção de escola necessária para ascensão social e profissional, como podemos constatar nas seguintes falas:

Mais tarde nós estaremos precisando de um advogado, nós estaremos precisando de um juiz de direito, então quer dizer que então vamos estar, cada vez mais apertado, né? Essa é a oportunidade que estamos tendo. Então vamos estar buscando esse meio para que possamos levar a coisa mais certa, porque hoje em dia, de uma hora pra outra, não está sendo fácil, então precisamos estar aprofundando essa questão de escola. (Pai de aluno)

Quem não tem estudo também sofre na cidade, porque hoje em dia quem tem estudo pode ter um trabalho... um serviço bom, ganhar um bom dinheiro, mas quem não tem, tem que pegar no pesado pra poder ganhar o... o seu dinheiro pra sustentar sua família. (Professor)

A luta pela garantia de seus direitos é recorrente nas vozes paresi, localizando a língua portuguesa como instrumento essencial nesta luta. Há que se registrar aqui que toda a legislação brasileira está organizada numa série de compêndios, escritos em língua portuguesa, dentro de um padrão normativo gramatical (ininteligível até para muitos falantes da língua portuguesa), aí incluídas as legislações específicas que regulamentam a questão indígena. Isto é perfeitamente percebido nas falas que seguem:

É... é muito importante porque cada ano, cada... cada ano... nós índios, estamos mais apertados por causa de fazendeiros, assim na luta do nosso direito... como podemos viver? Como podemos levar a vida assim, pode ser na al- 
deia, como na cidade, como pode se defender? Como pegar um emprego? (Pai de aluno)

[...] primeiro porque, se as crianças não prepararem, um dia, vamos supor, se o Governo... o Congresso, principalmente o Congresso aprovar uma lei que possa estar reduzindo as terras indígenas, aí os índios não vão entender de direito. Talvez não vão conseguir manifestar, procurar seus direitos e a sobrevivência vai ficar muito mais difícil. (Professor)

Outra questão levantada pelos entrevistados e que se revela importante, por causa da freqüência nos depoimentos, refere-se à questão da continuidade dos estudos na cidade, já que a oferta nas escolas da aldeia é somente até a quarta série do ensino fundamental. Uma das justificativas dos entrevistados para considerarem a escola da aldeia "fraca" centra-se no fato de serem constantes as reprovações e desistências, enquanto, os alunos vão continuar seus estudos nas escolas da cidade. Alguns entrevistados analisam este fracasso como resultante da falta de compreensão e uso da língua portuguesa:

[...] porque se você só fala na língua quando você vai pra cidade você vai ter dificuldade pra falar, pra entender, pra fazer as atividades, entender o que a professora ou outra pessoa tá falando pra você. Se você não sabe, uma pessoa manda você fazer uma coisa, pegar alguma coisa se você não conhece, você não vai ser capaz de pegar, isso eu acho que é importante (Professor)

Então na cidade ele já reprova por causa que ele não entende quase tudo da língua portuguesa, sabe escrever tudo né? Mas na fala assim, na hora de responder algumas perguntas na prova, então ele fica com muita dificuldade para responder. (Pai de aluno)

Para participarem das dinâmicas construídas pela sociedade nacional, as minorias reestruturam-se e ressignificam-se, com instrumentos próprios e adquiridos, negociando sua posição rotineiramente nas relações sociais. Admitir a escola na aldeia, com todos os seus rituais de saberes e valores ocidentalizados, pode não significar a submissão ou mesmo a rendição à homogeneização cultural desses grupos, mas ao contrá- rio, pode representar uma ação de resistência a esse processo, como nos alerta Silva (2000), que entende a escolarização para as comunidades indígenas como instrumento e forma de decifrar a realidade diante da situação de contato, afirmando que este ato "longe de ser uma 'adesão' (simples) a nosso modelo, é, nesse sentido, uma estratégia de resistência” (p. 65). Esta postura também é compartilhada por Bonin (1998, p. 140): "Decifrar este mundo e as regras nas quais se estrutura o sistema de dominação é, então, estratégia de resistência. O conhecimento nestes termos é instrumento para os povos indígenas na luta para a mudança nas relações com a sociedade envolvente".

\section{Conclusão}

Em meu entendimento, a escola apresenta-se na fronteira. De um lado, as discussões promovidas pelos movimentos dos professores indígenas, com o amparo legal que lhes legitima o direito a uma escola diferenciada, que valorize suas características culturais tradicionais e privilegie sua língua materna. De outro, a representação construída de um instrumento que se apresente em condições de prover a comunidade com informações suficientes para permitir o acesso às dinâmicas da sociedade ocidentalizada, de forma que eles possam usufruir todos os bens de direito de qualquer cidadão brasileiro.

Se, no passado histórico, a luta dos indígenas brasileiros fazia-se empunhando armas, atualmente os Paresi entendem que sua principal arma é o domínio da língua portuguesa. Considerando esta adesão a ela como uma estratégia de resistência, utilizo-me novamente dos apontamentos de Silva (2000) e compreendo que, além de resistência, configura-se num instrumento de luta de poderes, entendido aqui na perspectiva de Foucault, como uma ação sobre outra ação. Essas estratégias de poderes estão entrelaçadas, difusas, numa "rede capilar", conforme as palavras do filósofo.

O Paresi compreende que toda dinâmica da sociedade envolvente está estruturada sob a língua nacional; desta forma, sem o domínio da mesma, não há como transitar e negociar com a sociedade envolvente. 
Dominando-a ele pode estabelecer uma relação de luta, marcando sua posição na sociedade dos "civilizados". Neste sentido, o uso e domínio dos códigos simbólicos da língua portuguesa prestam-se ao exercício de poder. Dominando-a poderão ter acesso a todos os documentos que lhes garantem os direitos legitimados nas legislações, em todas as esferas e assim, acreditam que não poderão mais ser enganados. Não precisariam mais de "brancos" para reivindicar e falar por eles.

Acreditam os Paresi que os conhecimentos escolares, tendo como requisito a compreensão da língua portuguesa, darão subsídios para continuarem seus estudos nas escolas da cidade, até mesmo cursando o ensino superior, de forma que no futuro tenham os seus advogados, juízes de direito, agrônomos, professores etc. Assim, constroem a representação de que a língua portuguesa, por meio da escolarização nas aldeias, se constituirá no instrumento que viabilizará a inserção do Paresi nas mesmas condições dos nãoíndios, em termos de status profissional e social.

Neste sentido, o conflito concentra-se em construir uma escola diferenciada atendendo a especificidades da cultura paresi, valorizando a língua materna, sem, no entanto, levar os próprios Paresi a sentiremse "diferentes", distanciados de uma política nacional escolar que lhes acena igualdade de condições aos demais cidadãos brasileiros. Circulando num mundo letrado, o domínio da leitura e escrita da língua nacional, assim como de todos os seus códigos normativos, revela-se atualmente a alternativa para estabelecer as relações de negociação necessárias para a manutenção de suas identidades. Esta questão ainda se coloca como um desafio para a comunidade paresi.

MARIA HELENA RODRIGUES PAES, mestre em educação pela Universidade Federal do Rio Grande do Sul, é docente da Universidade do Estado de Mato Grosso, no campus Universitário de Tangará da Serra-MT e pesquisadora do NECCSO - Núcleo de Estudos sobre Currículo, Cultura e Sociedade da UFRGS. Publicou: A escolarização: um processo de produção de identidades híbridas. In: Igualdade e diversidade na educação. Anais do XI Encontro Nacional de Didática e Prática de Ensino (Goiânia: ENDIPE, 2002); Escola híbrida: um olhar dos estudos culturais aos atuais dilemas da escola indígena nas aldeias Paresi de Tangará da Serra-MT. Anais do Simpósio Nacional "Discurso, Identidade e Sociedade" (Rio de Janeiro: 2001); As vergonhas do Brasil 500 Anos. Diário da Serra. Tangará da Serra: 2000, p. 4. E-mail: mhninha@terra.com.br

\section{Referências bibliográficas}

ARELLANOS, Vilma Duque, FREEDSON-GONZÁLES, Margaret, (1998). Hacia um diagnóstico de la realidad educativa de los pueblos indígenas de la región mesoamericana: el caso de los Altos Chiapas, México. In: Secretaria de Estado de Educação/Conselho de Educação Escolar indígena de Mato Grosso. Anais da Conferência Ameríndia de Educação. Anais do Congresso de Professores Indígenas do Brasil. Cuiabá.

ARFUCH, Leonor, (1995). La entrevista, una invención dialógica. Buenos Aires: Paidós.

BANDEIRA, Maria de Lourdes, (1997). Formação de professores índios: limites e possibilidades. In: SECCHI, Darci (org.). Urucum, jenipapo e giz. Cuiabá: Entrelinhas.

BONIN, Iara Tatiana, (1998). Professores indígenas: resistência em movimento. In: Secretaria de Estado de Educação/Conselho de Educação Escolar indígena de Mato Grosso. Cuiabá. Anais da Conferência Ameríndia de Educação. Anais do Congresso de Professores Indígenas do Brasil.

CANCLINI, Néstor Garcia, (1999). Consumidores e cidadãos; conflitos multiculturais da globalização. $4^{\mathrm{a}}$ ed. Rio de Janeiro: Editora UFRJ.

HALL, Stuart, (2000). A identidade cultural na pós-modernidade. Trad. Tomaz Tadeu da Silva, Guacira Lopes Louro. $4^{\mathrm{a}}$ ed. Rio de Janeiro: DP\&A.

SILVA, Rosa Helena Dias da, (2000). A autonomia como valor e articulação de possibilidades: o movimento dos professores indígenas do Amazonas, de Roraima e do Acre e a construção de uma política de educação escolar indígena. In: MORI, Angel Corbera, NASCIMENTO, Adir Casaro. Educação indígena e interculturalidade, Cadernos CEDES, Campinas: CEDES, $\mathrm{n}^{\mathrm{o}} 49$, p. $62-75$. 
mechanisms operate to govern childhood. This research, inspired by Michel Foucault's ideas, seeks to show how mechanisms of power/knowledge concerning childhood are produced within pedagogical relationships. In this article, an analysis of the "government" of childhood is undertaken, examining propositions presented in the document and stressing the ways technologies of the self operate. Related to political technologies and governmental rationalities this work emphasises the $R C N$ as a mechanism that proposes to produce children's subjectivities and that aims to organise, impart and control the circulation of knowledge in early childhood institutions.

Key-words: early childhood education, children's subjectivities, technologies of the self, power mechanisms.

Nilma Lino Gomes

Trajetórias escolares, corpo negro e cabelo crespo: reprodução de estereótipos e/ou ressignificação cultural?

O trabalho estabelece uma articulação entre os processos educativos escolares e não-escolares e a construção da identidade negra. Discutem-se as representações e as concepções semelhantes, diferentes e complementares sobre o corpo negro e o cabelo crespo, construídas dentro e fora do ambiente escolar, a partir de lembranças de adolescentes e jovens negras entrevistadas durante a realização de uma pesquisa etnográfica sobre corpo e cabelo como ícones identitários em salões étnicos. Pretende-se compreender o significado social do cabelo e do corpo e os sentidos a eles atribuídos pela escola e pelos sujeitos negros entrevistados. $\mathrm{O}$ entendimento desse contexto revela que o corpo como suporte de construção da identidade ainda não tem sido uma temática privile- giada nos estudos sobre relações raciais e educação.

Palavras-chave: educação, identidade negra, corpo.

School trajectories, black skin and

Afro hair: reproduction of

stereotypes and/or cultural resignificance

This study establishes an articulation between school and non-school educational processes and the construction of Negro identity. It discusses the representations and similar, different and complementary conceptions about the Negro body and afro hair, constructed within and without the school environment, based on the memories of adolescent and young Negros interviewed during an ethnographic research on body and hair as identity icons in ethnic hairdressing salons. The intention is to understand the social significance of hair and body and the meanings attributed to them by the school and by the Negro subjects interviewed. The understanding of this context reveals that the body as a support for the construction of identity has not been a theme given prominence in studies on racial relations and education.

Key-words: education, negro identity, body.

Maria Helena Rodrigues Paes A questão da língua na escola indígena em aldeias Paresi de Tangará da Serra-MT

Os índios Paresi, de Tangará da Serra-MT, embora de grande apego aos elementos da sua cultura tradicional, vivem um processo de intensas relações com a sociedade envolvente, ressignificando seus hábitos tradicionais e os incorporados da cultura ocidentalizada, sendo a escolarização formal um instrumento essencial para transmissão dos códigos simbólicos da cultura ocidentalizada. Em um mo- mento de transição entre um modelo de escola tradicional para um modelo que atenda às especificidades da realidade local, este trabalho propõe uma reflexão, à luz dos estudos culturais, do discurso da valorização da língua portuguesa na rotina escolar, não entendendo esta opção como sobreposição aos valores da cultura tradicional, num processo de homogeneização, mas como uma ferramenta e um instrumento de poder, que visa marcar o lugar do Paresi na sociedade envolvente.

Palavras-chave: educação indígena, hibridização, linguagem.

The language question in the present dilemmas of the indigenous school in paresi villages in Tangará da Serra in the State of Mato Grosso

The Paresi Indians, from Tangará da Serra, in the State of Mato Grosso, although greatly attached to elements of their cultural tradition, experience a process of intense relations with the society by which they are surrounded, giving new meaning to their traditions and to those incorporated from the westernised culture. In this process, formal schooling has proved an essential instrument for the transmission of symbolic codes of westernised culture. In a phase of transition from a traditional school model to a model which attends the specificities of local reality, this paper proposes a reflection, in the light of cultural studies, on the discourse which values the use of Portuguese language in school routine, not understanding this option as an imposition on the values of the traditional culture as part of a process of homogenisation but as a tool and powerful instrument which aims to establish the place of the Paresi in the surrounding society.

Key-words: indigenous education, hybridisation, language. 